\title{
Efficacy and Safety of Ombitasvir/Paritaprevir /Ritonavir \pm Dasabuvir \pm Ribavirin in Treatment of Patients With Chronic Hepatitis C
in the Republic of Srpska: a Real-Life Study
}

Antonija Verhaz ${ }^{1,2}$, Zdravka Kezić1, Miloš P. Stojiljković ${ }^{3}$, Ranko Škrbić ${ }^{3}$

\begin{abstract}
Background: The purpose of this study was to assess the antiviral efficacy and safety of the direct-acting antivirals (DAAs) in therapy of chronic hepatitis $\mathrm{C}$ virus (HCV) infection.

Methods: This real-life multi-centric study was performed at the Clinic for Infectious Diseases, University Clinical Centre of the Republic of Srpska, Banja Luka and it included a total of 89 patients. All patients received the adequate doses of ombitasvir (OBV)/ paritaprevir (PTV)/ritonavir (RTV) + dasabuvir (DSV) plus ribavirin (RBV). RBV was given to all patients except to those with HCV sub-genotype 1 b. DSV was not administered to patients infected with HCV genotype 4. For the majority of patients the treatment duration was 12 weeks. For ten patients with liver cirrhosis the duration of treatment was 24 weeks. Viraemia was assessed at three points in time: at baseline, 12 or 24 weeks after the beginning of treatment (end of treatment response - ETR), and 12 weeks after the end of treatment (sustained viral response - SVR).

Results: Complete ETR after 12 weeks of treatment was achieved in 79 patients, while in 10 high-risk patients it was achieved after 24 weeks of treatment. Full SVR was recorded in 88 patients 12 weeks after the end of treatment. This therapy was well tolerated and mild adverse effects were recorded in only 10 patients.

Conclusion: Treatment of patients with chronic HCV infection with OBV/PTV/ $\mathrm{RTV}+\mathrm{DSV}+\mathrm{RBV}$ resulted in excellent antiviral activity and mild adverse events.

Key words: hepatitis C virus, ombitasvir, paritaprevir, ritonavir, dasabuvir, ribavirin.
\end{abstract}

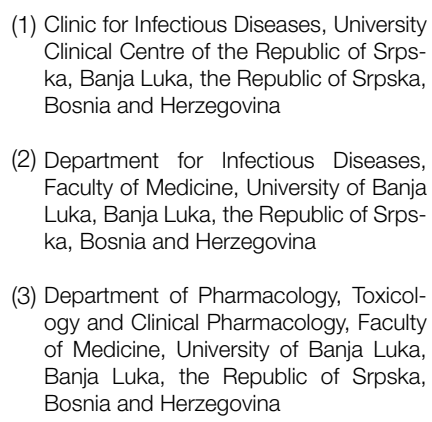

(1) Clinic for Infectious Diseases, University Clinical Centre of the Republic of Srpska, Banja Luka, the Republic of Srpska, Bosnia and Herzegovina

(2) Department for Infectious Diseases, Faculty of Medicine, University of Banja Luka, Banja Luka, the Republic of Srpska, Bosnia and Herzegovina

(3) Department of Pharmacology, Toxicology and Clinical Pharmacology, Faculty of Medicine, University of Banja Luka, Banja Luka, the Republic of Srpska, Bosnia and Herzegovina

\section{Correspondence:}

ANTONIJA VERHAZ

E: antonija@blic.net.

\section{ARTICLE INFO}

Received: 19 May 2019 Revision received: 5 June 2019 Accepted: 12 June 2019

\section{INTRODUCTION}

Hepatitis $\mathrm{C}$ virus (HCV) infection is the leading cause of chronic liver disease, and the number of chronically infected persons is estimated to be nearly 71 million worldwide ${ }^{1,2}$. Approximately $30 \%$ of all patients with chronic HCV infection develop extensive liver fibrosis and cirrhosis within two to three decades from disease onset, and this infection is also associated with increased risk of hepatocellular carcinoma ${ }^{3}$. According to World Health Organisation (WHO) data, the prevalence of HCV infection in Bosnia \& Herzegovina is $1.5 \%{ }^{4}$. Recent study in healthy blood donors suggests that the prevalence is only $0.27 \%$. Our results of genotyping in hospitalised patients with $\mathrm{HCV}$ infection showed that the predominant genotype is type $1(73.3 \%)$, followed by type $3(21.6 \%)$, type $4(4.4 \%)$ and type 2 (0.7\%; unpublished data).

Over the years the standard treatment of chronic HCV infection was combination of pegylated interferon a (PEG-IFN) and ribavirin (RBV). However, the efficacy of this treatment was limited, providing the sustained viral response 
(SVR) in $41-73 \%$ of treated patients ${ }^{6}$. In patients infected with most prevalent genotype 1 the SVR was achieved in only 40-50\% of patients7. DAA agents that target multiple steps in the HCV replication life cycle have been developed and are highly effective, safe and require a short treatment duration. DAAs have been approved by the Food and Drugs Administration (FDA), including the $\mathrm{NS}_{3}$ protease inhibitors glecaprevir, grazoprevir and voxilaprevir; the $\mathrm{NS}_{5} \mathrm{~B}$ nucleotide inhibitor sofosbuvir; and the NS5A inhibitors velpatasvir, pibrentasvir, elbasvir and ledipasvir. There are now three pan-genotypic DAA regimens: sofosbuvir plus velpatasvir, glecaprevir plus pibrentasvir, and sofosbuvir plus velpatasvir plus voxilaprevir. Other DAA regimens are all genotype-specific, and each genotype will be considered individually here.

Since the resistance rate and numerous side effects of the PEG-IFN-based regimens was high, the combination of ombitasvir (OBV)/paritaprevir (PTV)/ritonavir (RTV) + dasabuvir (DSV), the second generation of direct acting antiviral (DAA) drugs, was introduced.The results of pivotal trials and real-world data with this type of treatment were excellent, with reported SVR rates of more than $93 \%{ }^{8,9}$.

The aim of this prospective, multicentre, real-life clinical study was to evaluate the efficacy and safety of the new DAA therapeutic regimen in patients with chronic $\mathrm{HCV}$ infection in $\mathrm{Re}-$ public of Srpska.

\section{METHODS}

This real-life clinical study was performed in Clinic for infectious diseases University clinical centre Republic of Srpska, Banja Luka. Diagnostic and treatment approach to these patients was inspired by AMBER study ${ }^{9,10}$. A total of 89 patients included in this study were of both genders, with chronic HCV infection, genotype 1 or 4, previously treated (non-responders or relapse patients) or treatment-naïve, with or without liver cirrhosis. Anatomical status of their livers was assessed by elastography (fibrosis scores Fo-F4), while the hepatic functional status was assessed by values of bilirubin, albumine, international normalised ratio (INR), alanine transaminase (ALT), aspartate transaminase (AST) and serum creatinine concentration. Based on these parameters Child-Pugh score and Model for End-stage Liver Disease (MELD) score were calculated in order to assess the existence of liver dysfunction. The following haematological parameters were also estimated: haemoglobin and alpha-fetoprotein concentrations (AFP), and red blood cell (RBC), white blood cell (WBC) and platelet (PTL) counts.

All patients enrolled in this study received the dose of OBV/PTV/RTV $12.5 \mathrm{mg} / 75 \mathrm{mg} / 5 \mathrm{mg}$ (Viekirax, AbbVie GmbH, Germany), two tablets as a morning dose and DSV $250 \mathrm{mg}$ (Exviera AbbVie GmbH, Germany), dose of $500 \mathrm{mg} /$ day divided in two doses. The dose of RBV (200 mg tablets) was $1000 \mathrm{mg} /$ day for patients weighing $<75 \mathrm{~kg}$ or $1200 \mathrm{mg} /$ day for patients weighing $>75 \mathrm{~kg}$ divided in two doses. The dose of RBV was modified or discontinued during the therapy in patients who developed severe adverse effects or laboratory abnormalities, such as anaemia.

RBV was given to all patients except to those with HCV sub-genotype $1 \mathrm{~b}$. DSV was not administered to patients infected with HCV genotype 4. For the majority of patients the treatment duration was 12 weeks. Duration of treatment was extended to 24 weeks in high-risk patients, i.e. patients with liver cirrhosis. Compensated cirrhosis defined as Child-Pugh score $\leq 6$ at screening by FibroScan (Echosens, Paris, France) score $\geq 14.6 \mathrm{kPa}$ within 6 months of screening. In general, individuals with compensated cirrhosis have mild hepatic impairment (Child-TurcottePugh class A).

Viraemia was assessed at four points in time: at baseline, four weeks after beginning of treatment (rapid viral response, RVR), 12 or 24 weeks after beginning of treatment (end of treatment response, ETR), and 12 weeks after the end of treatment (sustained viral response, SVR). Number of replications of viral RNA was expressed in $\mathrm{IU} / \mathrm{ml}$. HCV levels were obtained by quantitative PCR essay. Viral RNA detection limit was $\geq 12 \mathrm{IU} / \mathrm{ml}$. Descriptive statistics such as calculation of mean values (ME) and their standard deviations (SD) were used.

\section{RESULTS}

A total of 89 patients with HCV infection was included. Sixty patients were previously treated with PEG-IFN and RBV and naive patients were 
29. Among them, 51 patients were null-responders, in 3 patients previous therapy was discontinued due to side effects, while 6 were relapse patients (Table 1). Nearly half of the patients included in this study (57.30\%) belonged to the difficult-to-treat group according to the fibrosis stage $\left(\mathrm{F}_{3} / \mathrm{F}_{4}\right)$. Only three out of 89 patients were infected with HCV genotype 4, and the rest of them belonged to genotype 1 . In half of them sub-genotyping was performed and genotypes $1 \mathrm{a}$ and $1 \mathrm{~b}$ were almost equally represented, while two patients were infected with both HCV $1 \mathrm{a}$ and $1 \mathrm{~b}$ sub-genotypes. Initial viraemia varied over the large range of values $\left(222 \times 10^{3}-101 \mathrm{x}\right.$ $10^{6} \mathrm{IU} / \mathrm{ml}$; with median $3.759 \times 10^{6} \mathrm{IU} / \mathrm{ml}$ ) with the mean value of $10.15 \times 10^{6} \mathrm{IU} / \mathrm{ml}$. Similarly, MELD score was 4.50 , as additional proof of minimal level of liver dysfunction. Accordingly, all the biochemical parameters of liver function were within the normal range of values, which also goes for haematological parameters (Table 1).

RVR was documented in only 12 patients. Eleven of them showed no HCV presence, while one patient had low viral concentration. Complete ETR after 12 weeks of treatment was achieved in 79 patients, while in 10 high-risk patients it was achieved after 24 weeks of treatment. Full SVR was recorded in 88 (98.9\%) patients 12 weeks after the end of treatment.

The therapy with DAAs was well tolerated and adverse events were recorded in only 10 patients; two of them developed anaemia, two of them had fatigue,one had headache, five had higher total bilirubin level. These side effects were not the reasons for discontinuation of therapy, but in one case the reduction of RBV dose was needed due to anaemia. Only 43 patients (48.31\%) had concomitant medication, which included: benzodiazepines, antihypertensive drugs, bronchodilators, antipsychotics, antidepressants, $\mathrm{H} 2$ blockers, oral diabetes drugs, insulin, calcium and vitamin D3 supplementation.

\section{DISCUSSION}

The presented real-life data showed very high efficacy (100\% ETR and 98.9\% SVR12) of the new DAAs (OBV/PTV/RTV + DSV + RBV) in patients with chronic HCV infection. This is in full accordance with results of other studies 9-13.
Table 1: Baseline demographical and clinical characteristics.

\begin{tabular}{|c|c|}
\hline Parameters & Study population $(n=89)$ \\
\hline Age, years $(+S D)$ & $45.89 \pm 9.98$ \\
\hline Gender, n (\%) & $89(100)$ \\
\hline Male & $58(65.16)$ \\
\hline Female & $31(34.84)$ \\
\hline Treatment history, n (\%) & $89(100)$ \\
\hline Naïve & $29(32.58)$ \\
\hline Null-responder & $51(57.30)$ \\
\hline Relapser & $6(6.74)$ \\
\hline Discontinued & $3(3.37)$ \\
\hline Fibrosis stage, $\mathrm{n}(\%)$ & $89(100)$ \\
\hline F0 & $17(19.10)$ \\
\hline F1 & $8(8.98)$ \\
\hline F2 & $9(10.11)$ \\
\hline F3 & $21(23.59)$ \\
\hline F4 & $34(38.20)$ \\
\hline Unknown & $4(4.49)$ \\
\hline HCV genotype, n (\%) & $89(100)$ \\
\hline $1 \mathrm{a}$ & $25(28.08)$ \\
\hline $1 \mathrm{~b}$ & $34(38.20)$ \\
\hline $1 a+1 b$ & $5(5.61)$ \\
\hline 1 (sub-genotype not available) & $22(28.08)$ \\
\hline 4 & $3(3.37)$ \\
\hline HCV RNA level x106 IU/ml ( \pm SD) & $9.07 \pm 2.15$ \\
\hline MELD score (mean \pm SD) & $4.50 \pm 0.62$ \\
\hline Albumin, g/l ( \pm SD) & $45.26 \pm 2.25$ \\
\hline Bilirubin, mmol/l ( \pm SD) & $14.60 \pm 10.20$ \\
\hline INR & $1.09 \pm 0.30$ \\
\hline Creatinine, mmol/l ( \pm SD) & $79.23 \pm 15.23$ \\
\hline ALT, IU/I ( \pm SD) & $67.34 \pm 32.10$ \\
\hline AST, IU/I ( \pm SD) & $42.60 \pm 22.00$ \\
\hline Haemoglobin, g/l ( \pm SD) & $143.22 \pm 13.00$ \\
\hline $\mathrm{RBC}, \mathrm{x} 1012 / \mathrm{l}( \pm \mathrm{SD})$ & $4.79 \pm 0.60$ \\
\hline WBC, $x 109 / I( \pm$ SD) & $6.66 \pm 2.25$ \\
\hline PLT, x109/l ( \pm SD) & $198.10 \pm 46.20$ \\
\hline AFP, ng/ml ( \pm SD) & $10.14 \pm 11.08$ \\
\hline
\end{tabular}

n-number of patients; HCV-Hepatitis C Virus; RNA-Ribonucleic Acid; MELD-Model for End-stage Liver Disease; INR-International Normalized Ratio; ALT-Alanine Aminotransferase; AST-Aspartate Aminotransferase; RBC-Red Blood Cells; WBC-White Blood Cells; PLT-Platelets; AFP-Alpha-Fetoprotein.

Majority of our patients (86/89) belonged to the genotype 1 , while only 3 patient belonged to genotype 4. This is in full accordance with European ${ }^{9,10,14}$ and US real-world data ${ }^{15}$ where predominant type was also genotype 1 , while in 
the Middle East most of the HCV infections are caused by genotype $4^{13}$.

RVR data suggest very rapid onset of action of DAAs with null viraemia in $91.66 \%$ of available patients. This result is in line with the Polish study were RVR was achieved in $69.23 \%{ }^{10}$. ETR and SVR data showed 100\% direct antiviral effectiveness of the used therapeutic regimen which was partly due to the well preserved hepatic function. Our results are in accordance with systematic review data of 19 real-world studies which included a total of 5548 patients and registered the overall SVR of $97 \%{ }^{11}$.

The tolerability of the new DAAs was acceptable with minor adverse events registered in 10/89 patients. The type of adverse events was similar

\section{ACKNOWLEDGEMENTS}

None.

\section{REFERENCES}

1. Hepatitis $\mathrm{C}$ - factsheets 2017 [Internet]. Geneve $(\mathrm{CH})$ : World Health Organization (WHO); 2017. [updated 2017 Oct 14, cited 2017 Nov 15]. Available from: htpp://www.who.int/mediacentre/factsheets/fs164/ en/

2. Messina JP, Humphreys I, Flaxman A, Brown A, Cooke GS, Pybus OG, et al. Global distribution and prevalence of hepatitis $\mathrm{C}$ virus genotypes. Hepatology 2015;61:77-87.

3. Parkin DM. The global health burden of infection-associated cancers in the year 2002. Int $J$ Cancer 2006;118:3030-44.

4. Hepatitis $\mathrm{C}$ - factsheets 2014 [Internet]. Geneve $(\mathrm{CH})$ : World Health Organization (WHO); 2015. [cited 2015 Jan 15]. Available from: http://www.who.int/mediacentre/factsheets/fs164/en/, accessed on: 15.01.2015.

5. Petrović J, Salkić NN, Ahmetagić S, Stojić V, Mott-Divković S. Prevalence of chronic hepatitis B and hepatitis $\mathrm{C}$ among first time blood donors in Northeast Bosnia and Herzegovina: en estimate of prevalence in general population. Hepat Mon 2011;11(8):629-33.

6. Desmond CP, Roberts SK, Dudley F, Mitchell J, Day C, Nguyen S, et al. Sustained virological response rates and durability of the response to interferon-based therapies in hepatitis $\mathrm{C}$ patients treated in the clinical setting. J Viral Hepat 2006;13:311-5.

7. European Association for Study of Liver. EASL recommendations on treatment of hepatitis C 2015. J Hepatol 2015;63:199-236. to those published by Flisiak $\mathrm{R}$ at al. ${ }^{10}$, but the percentage was much lower in our study (11.23\% vs. $72.20 \%$ ). The dose of RBV in current study had to be reduced due to the occurrence of anaemia in only 2 patients, which is much lower than in other studies ${ }^{10-14}$. No serious adverse events were registered in our study. The possible reason for both, 100\% of antiviral response and absence of serious adverse events, could be explained by more homogeneous group of younger (mean age $45.89 \pm 9.98$ ) patients with well-preserved liver function than in the other studies ${ }^{16}$.

In conclusion, this real-life cohort study clearly showed an excellent antiviral efficacy and tolerability of the new DAAs treatment (OBV/PTV/ $\mathrm{RTV}+\mathrm{DSV}+\mathrm{RBV}$ ) in patients infected with HCV genotypes 1 and 4 .

\section{CONFLICT OF INTEREST}

None.

8. Lucejko M, Parfieniuk-Kowerda A, Flisiak R. Ombitasvir/paritaprevir/ritonavir plus dasabuvir combination in the treatment of chronic HCV infection. Expert Opin Pharmacother 2016;17:1153-64.

9. Flisiak R, Janczewska E, Wawrzynowicz-Syczewska M, Wiercinska-Drapalo A, Zarebska-Michaluk D, Fleischer-Stepniewska K, et al. Efficacy and safety of Parytaprewir/r/Ombitaswir and Dazabuwir with or without Ribavirin in real life therapy of Polish patients with chronic hepatitis $\mathrm{C}$ - an interim analysis of AMBER study data. Clin Exp Hepatol 2015;1(2):84.

10. Flisiak R, Janczewska E, Mawrzynowicz-Syczewska M, Jaroszewicz J, Zarebska-Michaluk D, Nazzal K, et al. Real-world effectiveness and safety of ombitasvir/paritaprevir/ritonavir + dasabuvir + ribavirin in hepatitis C: AMBER study. Aliment Pharmacol Ther 2016;44:946-56.

11. Pogorzelska J, Flisiak R. Real-world experience with ombitasvir/paritaprevir boosted with ritonavir and possibly combined with dasabuvir and ribavirin in HCV infection. Clin Exp Hepatol 2016;2:34-7.

12. Lawitz E, Makara M, Akarca US et al. Efficacy and safety of ombitasvir, paritaprevir, and ritonavir in an open-label study of patients with genotype $1 \mathrm{~b}$ chronic hepatitis $\mathrm{C}$ virus infection with and without cirrhosis. Gastroenterology 2015;149:971-80.

13. Alswat KA, Babatin MA, Abdelrahman AA, Al-Hamoudi WK, Alghamdi AS, Abdo A, Sanai FM. Treatment of chronic hepatitis $\mathrm{C}$ genotype 4-infected patients with 
ombitasvir/paritaprevir/ritonavir plus ribavirin: Real life data from Saudi Arabia. Hepatology 2016;64(1 Suppl):974A-975A.

14. Rodriguez-Osorio I, Cid P, Morano L, Castro A, Suarez M, Delgado M, et al. Real life experience with direct-acting antivirals agents against hepatitis $\mathrm{C}$ infection in elderly patients. J Clin Virol 2017;88:58-61.

15. McCombs J, Mc Ginnis J, Fox S, Tonnu-Mihara I. Analysis of the real world effectiveness of direct acting antivirals treatments of hepatitis $\mathrm{C}$ in large population.J Hepatol 2016; 64(2 Suppl):S2017.

16. Backus LI, Belperio PS, Shahoumian TA, Loomis TP, Mole LA. Comparative effectiveness of ledipasvir/ sofosbuvir \pm ribavirin vs. ombitasvir/paritaprevir/ ritonavir + dasabuvir \pm ribavirin in 6961 genotype 1 patients treated in routine medical practice. Aliment Pharmacol Ther 2016;44:400-10. 